\title{
Remote Experiments in Primary School Science Education
}

\author{
http://dx.doi.org/10.3991/ijoe.v9i5.2730 \\ M. Kostelníková ${ }^{1}$ and M. Ožvoldová ${ }^{1,2}$ \\ 1 Trnava University, Trnava, Slovakia \\ 2 Tomáš Bata University in Zlín, Zlín, Czech Republic
}

\begin{abstract}
The development of new information technologies enables remote experimentation suitable for primary school science education. On the basis of the pilot research conducted in 2010 - 2011 we designed the research carried out on six Slovak primary schools in 2011 - 2012. Our main goal was to examine the influence of the project-based learning with the support of remote experiments on the pupils' scientific literacy development and the sustainability of the acquired knowledge and skills. The gained result confirmed the positive influence of the proposed methodology on the development of scientific literacy (encouraged by the State Educational Programme), the knowledge sustainability and the associated skills. Furthermore, the rise of the pupils' interest in the subject matter was affirmed.
\end{abstract}

Index Terms - project-based learning, remote experiments, science education, scientific literacy.

\section{INTRODUCTION}

Remote experiment (RE) - real and virtual - is a commonly used method to conduct laboratory works mainly at tertiary education [1] - [7]. REs can either supplant or supplement traditional hands-on experiments offering students the opportunities of experimentation with physical apparatus. Besides the obvious advantage in terms of manipulating with real experimental facilities, hands-on experiments are also known for their high costs associated with the required equipment, space, and maintenance staff [8]. The utilisation of REs is one of the potential solutions to overcome this shortcoming. Furthermore, research has shown that when used appropriately REs can bring a range of potential benefits, including the ability to share resources across multiple institutions, support access to facilities that would otherwise be inaccessible for cost or technical reasons, and provide augmentation of experimental experience [9].

While many examples of good practice at tertiary education are known, the role of REs within secondary [9] - [11] or even primary school science education is rarely investigated. And because experiments in basic science education play the decisive role - in transmitting or constructing knowledge, verifying scientific theories, or arousing students' interest - this area demands adequate attention from researchers.

The paper presents the possibility of the utilisation of REs in primary school physics education. After the brief analysis of the actual situation in Slovak primary school physics education, which indicates a need for change in the pedagogical approach, we acquaint with the research its methods, organization and gained results. The possible influence of REs on pupils' scientific literacy and the sustainability of knowledge are analysed and discussed. The attitudes of pupils towards REs are also introduced.

\section{The Current State of Slovak Science EducAtion}

The New Education Act was passed in Slovakia on 1 September 2008, and the Slovak State Educational Programme entered into force in 2009. It covers primary as well as secondary schools and sets down the changes in the field of curricula, number of teaching hours for individual subjects and requirements for teachers and students. Excessive emphasis on knowledge of encyclopaedic facts, often leading to rote learning, which were the most criticised aspects of the old education system, should be replaced by meaningful knowledge acquisition. Owing to this demand, teachers have to cope with the new structure of curriculum and implement interdisciplinary approaches to teaching and learning with the main objective: to prepare pupils/students for the knowledge society and further development of their key competencies.

In Physics and Chemistry, pupils/students should acquire knowledge mainly by means of experimental works leading to deeper understanding of basic scientific concepts. The main drawback of this philosophy lies in the insufficient lab equipment of the majority of primary and secondary schools, which cannot afford to build up an appropriate laboratory due to limited school funding. This obstacle can be bridged by the usage of REs. They allow a single apparatus to be shared across many schools [9]. Moreover, this apparatus is ready to be used 24/7 without the need to assemble it.

In accordance with the current paradigm of education, there are other factors promoting the implementation of REs in science education:

- In pursuance of the State Educational Programme, exploitation of modern Information and Communication Technologies (ICT) with the main stress on the modern interactive methods and strategies in teaching and learning are strongly supported;

- Public schools have obtained various modern ICT thanks to national and international projects aimed at the modernisation of Slovak primary and secondary schools - they have the necessary technical equipment for remote experimentation;

- Many teachers are developing their computer literacy through a variety of accredited courses, which increases the probability of successful integration of REs in education; 
External conditions are favourable for REs - teachers exhibit the necessary ICT skills, schools are equipped with computer rooms, and activities of this type are strongly encouraged by the State Educational Programme. Moreover, various studies prove REs implemented in education can either achieve comparable results as handson experiments, or can even increase the level of learning outcomes [12] - [15].

Before we can succeed with the implementation of REs in science education at primary schools, it is important to gain an insight into teachers' reactions to REs. To this end, we addressed a group of 38 science teachers, familiar with REs, in order to identify their attitudes towards REs. The survey with the detailed results is described elsewhere [16]. At this point, we consider it important to sum up briefly the main finding of the survey regarding teachers' attitudes towards REs. Although, predictably, they still prefer hands-on experiments, they see the potential power and effectiveness in REs. Though they revealed many heterogeneous opinions, the majority of them were positive. They appraised the utility of REs in the conduction of difficult experiments; as the solution in the case of the lack of experimental tools; ideal when combined with hands-on experiments; an option for afterschool activities etc. Contrarily, they criticized the frequent dropouts of various REs, passivity of students, or time-consumption of REs. The majority of them agreed on the view that they need to be provided with some methodological materials in order to utilize remote experiments in their praxis.

In this regard, we bring in one such example representing our research accomplished at six Slovak primary schools proving the efficiency of REs in primary school physics education. Specifically, using the REs and project-based learning; we concentrated on the teaching topic "Temperature measurement".

\section{RESEARCH AND THE RESULTS}

The research was focused on the possible development of the pupils' scientific literacy and the sustainability of the acquired knowledge and skills by means of the project-based learning with the support of REs. For this purpose we used the project assignment "Measuring Air Temperature in Different EU Countries" based on the simultaneous temperature measurements using three REs. Specifically, we used REs in e-laboratories located at the Trnava University in Trnava, Slovakia, Charles University in Prague, Czech Republic and University of Porto, Portugal. The main hypothesis of the research was: There is a significant relationship between the active work with REs and the development of scientific literacy.

The pedagogical research took place at six primary schools (four schools as test group (TG) and two as control group (CG)) in 2011 - 2012. The participants in the research were 156 seventh-grade Slovak primary school pupils (69 boys and 87 girls). A pedagogical experiment was designed, in which the independent variable was the work on the project and the dependent variables were:

- Scientific literacy - knowledge and work with data;

- Sustainability of knowledge and skills;

- Pupils' attitudes towards Physics and REs.

It was built on the findings and is the continuation of the pre-research conducted in $2010-2011$. The details of the pre-research were discussed elsewhere [17]. Its conclusions can be summarized as follows:

- The project designed for the purpose of the preresearch was confirmed as a proper way of implementation of REs in primary school physics education - this finding was in accordance with previous research, in which project-based learning was effectively utilised in primary school physics education on the topic of "Energy in nature, technology and society" [18].

- Despite its unconventionality in comparison with traditional education, the project fulfilled the demands of the national curriculum, and pupils working on the project scored higher in the didactic test in comparison with the control group.

- The pupils revealed predominantly positive attitudes towards remote experimentation.

\section{A. Real remote experiments in the research}

As the research was aimed at the utilization of REs in education, we implemented three remote meteorological stations in the project assignment (Fig. 1):

- Trnava, Slovakia: http://remotelab1.truni.sk;

- Prague, Czech Republic:

http://kdt-16.karlov.mff.cuni.cz/en/mereni.htm;

- Porto, Portugal:

http://experimenta.fe.up.pt/estacaometeorologica/index .php?lang=pt.

REs used in the research are open to all users without registration or the prerequisite of installing a special program (besides Java required in the first two REs).

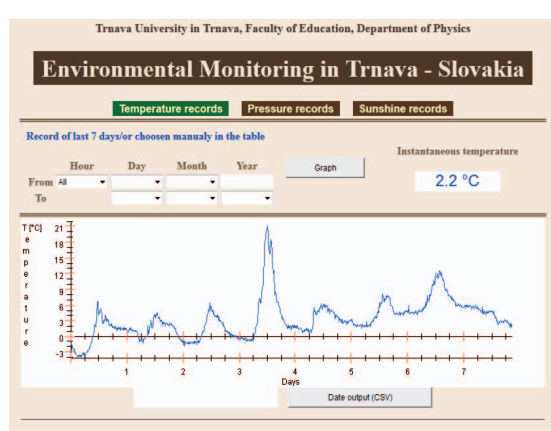

a)

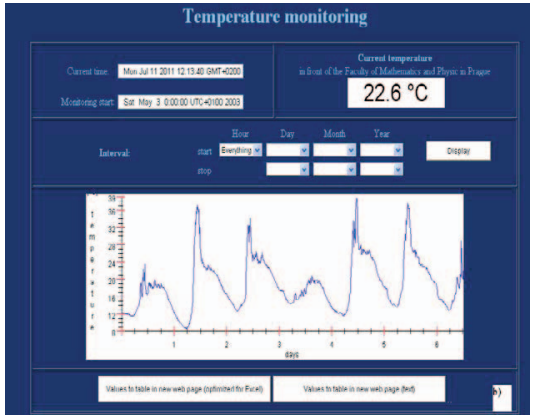

b)

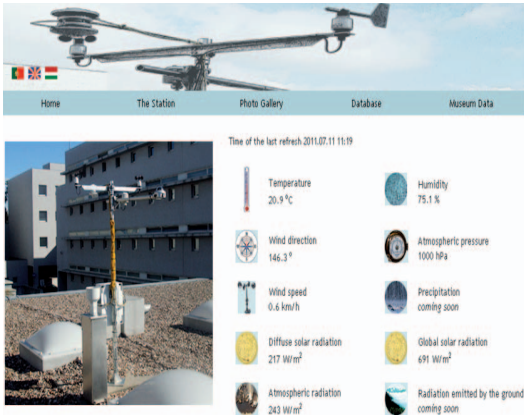

c)

Figure 1. Remote meteorological stations: Trnava, Slovakia (a), Prague, Czech Republic (b), Porto, Portugal (c) 
Slovak and Czech stations are based on the system ISES (Internet School Experimental System) [19], [20], which comprises both hardware and software solutions. The Slovak meteorological station monitors the temperature, the pressure, and the intensity of sunshine at the Faculty of Education, Trnava University in Trnava [21]. In the case of the Czech station, the background radiation is sensed in addition and the experiment is placed at the Faculty of Mathematics and Physics, Charles University in Prague [19]. More users may be connected to these experiments at a time.

Remote monitoring of physical variables in the Portuguese experiment is based on the system LabVIEW [22]. This remote laboratory contributes to the urban climate characterization of Porto. Several physical variables, such as temperature, wind velocity and direction within the Campus of Faculdade de Engenharia da Universidade do Porto are available every 10 minutes. All the data is recorded in a data base for its later use by anyone accessing the system.

The remote stations used in our research are sensor-type experiments [8]. The experiments platforms involving only sensors, or sensor networks, return sensor data to remote users, for monitoring and/or analysis purposes. The experiments demonstrate the possibility to monitor different physical variables with simple technical hardware and software across the Internet.

It is difficult to find the real RE appropriate for primary school physics education. And because remote meteorological stations are not interactive REs, they can be easily implemented to primary school physics education. The manipulation of these experiments is very simple, pupils can learn how to obtain remotely sensed data and how to process and evaluate them. These tasks were fulfilled in the work on the project.

\section{B. Project "Measuring Air Temperature in Different EU Countries"}

The prerequisite for the project designing was to meet the requirements defined by the State Education Programme for primary schools ISCED 2 [23] where we can find the following demands on pupils' activities, taken into consideration:

- Observations and measurements;

- Search for proper information, its processing and storing;

- Organization and planning of work;

- Graph analysis, its explanation and interpretation;

- Comparison of two or more graphs and identification of their common and different features;

- Using a computer to make a graph;

- Elaboration of the transferred meteorological data and design of a corresponding table;

- Presentation of the results.

Based on the above mentioned requirements, we included the following tasks in the project assignment:

- To choose the period of two weeks for data collection;

- To collect the data on the air temperature (with the appropriate sampling period - e.g. every six hours) and arrange it in a table;
- To plot the corresponding time dependence of the air temperature;

- To explore the changes in the temperature and to identify the maxima and minima;

- To calculate the average value of the temperature; to identify the greatest difference between the maximum and minimum of the day temperature;

- To show the independent and dependent quantities;

- To denote the average value of the temperature in the graph;

- To introduce the particular country from the point of view of its latitude and climate;

- To compare the data obtained with the data of other groups;

- To explore the relation between the temperature and the latitude;

- And to draw conclusions from these comparisons [17].

When comparing the possibilities of REs integrated in the project assignment with the hands-on temperature measurement or direct meteorological observations, we identify several advantages of using REs:

- Integration of various school subjects (Maths, IT, Physics, Geography, Foreign language);

- Option to work with the experiment without teachers' or adults' assistance (pupils processed the data at home);

- Time efficiency - huge amount of data gained without time-consuming manual recording;

- Access to archived data - option to study the process of climate changes;

- Higher measurement accuracy - precise time interval, random errors caused by an experimenter are excluded.

In the following, we present briefly the course of the research, in which we utilized the prepared project in primary school physics education.

\section{The course of the research and the results}

The summary of the activities during the research is shown in Tab. 1. As can be seen, the research was conducted in three steps: pre-research, project-based learning with the first testing, and finally the second testing and identifying of pupils' attitudes towards REs. In the paper we focus on the second and third step of the research.

Firstly, after establishing contacts with schools/teachers involved in the study, the pre-test was conducted in order to determine whether the prior knowledge of the pupils is comparable. The results of the descriptive statistics are presented in Tab. 2. The data was also subjected to deeper statistical analysis using Shapiro-Wilk normality test and non-parametric Mann-Whitney test $(\alpha=0.05)$. The evaluation of the data detected no significant difference $(p=0.714>\alpha)$ between the results of both groups of pupils. In accordance with this finding we could continue the research with the chosen groups. 
PAPER

REMOTE EXPERIMENTS IN PRIMARY SCHOOL SCIENCE EDUCATION

TABLE I.

THE COURSE OF THE RESEARCH

\begin{tabular}{|c|c|c|c|c|c|c|}
\hline \multirow[b]{2}{*}{ Groups } & \multicolumn{6}{|c|}{ Steps of the research } \\
\hline & \multicolumn{2}{|c|}{$\begin{array}{l}\text { Pre-research } \\
(2010 / 2011)\end{array}$} & \multicolumn{3}{|c|}{$\begin{array}{c}\text { Research }-1^{\text {st }} \text { testing } \\
\text { (November } 2011-\text { January 2012) }\end{array}$} & $\begin{array}{l}\text { Research }-2^{\text {nd }} \text { testing } \\
\text { (May-June 2012) }\end{array}$ \\
\hline $\begin{array}{c}\text { Test } \\
\text { group } 1\end{array}$ & $\begin{array}{l}\text { Education and project } \\
\text { \& REs }\end{array}$ & $\begin{array}{l}\text { Didactic test, } \\
\text { questionnaire }\end{array}$ & & & & \\
\hline $\begin{array}{l}\text { Control } \\
\text { group } 1\end{array}$ & Traditional education & Didactic test & & & & \\
\hline $\begin{array}{c}\text { Test } \\
\text { group } 2\end{array}$ & & & Pre-test & $\begin{array}{l}\text { Education } \\
\text { and project } \\
\text { \& REs }\end{array}$ & $\begin{array}{l}\text { Post-test, } \\
\text { questionnaire }\end{array}$ & Post-test, questionnaire \\
\hline $\begin{array}{l}\text { Control } \\
\text { group } 2\end{array}$ & & & Pre-test & $\begin{array}{l}\text { Traditional } \\
\text { education }\end{array}$ & Post-test & Post-test \\
\hline
\end{tabular}

After the pre-test, we implemented the experimental intervention in TG. The pupils were working with REs through the project assignment. Meanwhile, CG was educated in a traditional way and they were doing some practical meteorological observations - in accordance with the State Educational Programme ISCED 2.

In the end of this part of the research, both TG and CG were tested by the first post-test. The post-test was aimed at the theoretical knowledge and the practical skills (work with data in the form of graphs and tables). Together, these two parts examined how the scientific literacy was developed during the study of the given thematic unit. Pupils of TG gained a significantly better score (Tab. 2) in comparison with $\mathrm{CG}$ (the significant difference was proved by Mann-Whitney test - the overall score: $p=0.033$; practical tasks: $p=0.002$ ). They scored better in the whole test (difference in results $\Delta S=7.21 \%$ ) as well as in the practical part aimed at data processing $(\Delta S=$ $13.5 \%$ ).

Five months later, the pupils realized the second testing aimed at the measuring of the sustainability of knowledge and skills acquired during the work on the project. We used the identical test as in the first testing for the better analysis of the actual sustainability among TG pupils. TG pupils scored better again when comparing with CG pupils (the significant difference was proved by MannWhitney test - the overall score: $p=0.000$; practical tasks: $p=0.000)$. The increase in the difference between both groups was observed in the summary assessment of the test $(\Delta S=14.01 \%)$ as well as in its practical part $(\Delta S=$ $23.60 \%)$.

Besides the knowledge and skills we were also interested in pupils' attitudes towards the realized project and REs.
For their identification, we used two questionnaires. The first one, distributed after the realization of the project, consisted of 15 questionnaire items.

These were aimed at exploring pupils' relation to the Internet, REs, and the benefits of the project. They were encouraged to express their attitudes towards REs, and advantages and disadvantages of working with them. The second one, administered after the second testing, comprised a set of 11 unfinished sentences. This projective technique, in which the respondent is asked to finish a sentence for which the first word or words are given, can reveal respondents' attitudes or opinions on a certain topic.

We evaluated both research tools together to obtain the complex overview of pupils' attitudes. In the following, we present the most interesting findings.

$40 \%$ of pupils demanded more experiments carried out in the classroom. It supports the idea that children are naturally interested in such activities, and it also encourages us to implement more REs in primary school education. Another supporting finding is connected with pupils' fondness of computers and the Internet - the majority of pupils chose electronic presentation as an outcome of their project, and they also use the Internet very frequently - mainly for searching for information for school assignments or communicating with friends.

We identified the following activities from the project to be the most beneficial for the pupils involved in the research:

- Work with graphs;

- Work with tables;

- Cooperation;

TABLE II.

THE RESULTS OF DIDACTIC TESTS

\begin{tabular}{|c|c|c|c|c|c|c|c|c|c|c|}
\hline \multirow{4}{*}{ Groups } & \multicolumn{10}{|c|}{ Didactic tests } \\
\hline & \multirow{2}{*}{\multicolumn{2}{|c|}{ Pre-test }} & \multicolumn{4}{|c|}{ Post-test 1} & \multicolumn{4}{|c|}{ Post-test 2} \\
\hline & & & \multicolumn{2}{|c|}{ Summary } & \multicolumn{2}{|c|}{ Practise } & \multicolumn{2}{|c|}{ Summary } & \multicolumn{2}{|c|}{ Practise } \\
\hline & $\begin{array}{c}\text { Mean } \\
\text { [points } \\
\text { /\%] }\end{array}$ & St. dev. & $\begin{array}{c}\text { Mean } \\
\text { [points } \\
\text { /\%] }\end{array}$ & St. dev. & $\begin{array}{c}\text { Mean } \\
\text { [points } \\
{[\% \text { ] }]}\end{array}$ & St. dev. & $\begin{array}{c}\text { Mean } \\
\text { [points } \\
{[\%] \text { ] }}\end{array}$ & St. dev. & $\begin{array}{c}\text { Mean } \\
\text { [points } \\
/ \% \text { ] }\end{array}$ & St. dev. \\
\hline $\begin{array}{l}\text { Test } \\
\text { group }\end{array}$ & $\begin{array}{l}17.65 / \\
76.74\end{array}$ & 3.91 & $\begin{array}{l}15.65 / \\
68.04\end{array}$ & 4.50 & $\begin{array}{l}7.01 / \\
70.10\end{array}$ & 2.38 & $\begin{array}{l}15.45 / \\
67.19\end{array}$ & 2.57 & $\begin{array}{l}7.36 / \\
73.60\end{array}$ & 1.42 \\
\hline $\begin{array}{l}\text { Control } \\
\text { group }\end{array}$ & $\begin{array}{l}17.55 / \\
76.30 \\
\end{array}$ & 4.32 & $\begin{array}{l}13.99 / \\
60.83 \\
\end{array}$ & 4.88 & $\begin{array}{l}5.66 / \\
56.60 \\
\end{array}$ & 2.70 & $\begin{array}{l}12.23 / \\
53.18 \\
\end{array}$ & 3.25 & $\begin{array}{l}5.00 / \\
50.00 \\
\end{array}$ & 2.03 \\
\hline$\underset{[\text { points/\%] }}{\Delta}$ & \multicolumn{2}{|c|}{$0.10 / 0.44$} & \multicolumn{2}{|c|}{$1.66 / 7.21$} & \multicolumn{2}{|c|}{$1.35 / 13.50$} & \multicolumn{2}{|c|}{ 3.22/14.01 } & \multicolumn{2}{|c|}{$2.36 / 23.60$} \\
\hline
\end{tabular}


- Searching for information on the Internet;

- Making presentations.

On the other hand, the first three answers were also mentioned as problems causing - the reason for the overlapping is due to the novelty of such an activity. Before the project, pupils had not been used to processing a huge data package and evaluating it in a graphical form. As to the problems with cooperation, sometimes pupils were not able to meet at the same time.

In the final part of the analysis, we concentrated on the pupils' attitudes towards REs (Fig. 2) and the work on the project (Fig. 3). On the basis of their open answers we identified several categories.

The pupils' statements about REs can be categorised into four groups: interesting, difficult, easy to work with, and dull. As can be seen, positive attitudes (interesting, easy to work with) are prevailing. Even the category "difficult" can have a positive connotation: if the pupils have to work hard, their knowledge acquired during the activity is longer lasting (this statement corresponds with the results of the second testing aimed at the sustainability of pupils' knowledge).

Their utterances about the work on the project were divided into a group with positive statements (interesting, instructive, difficult, easy to work on, as good as expected, better than expected), and a group with negative statements (dull, as bad as expected, worse than expected). Again, the prevailing positive attitudes are obvious.

Furthermore, we managed to identify a positive shift in pupils' perception of Physics by $12 \%$ of respondents. And because the situation in Physics education is often referred to as critical [24], [25], we see a good sign in this finding. It is probable that REs, when implemented to science education appropriately and as soon as possible, have the power to motivate pupils for deeper study of science and natural world phenomena.

To conclude this part of the analysis, we can proclaim that pupils' reactions towards REs as well as their interconnection with the work on the project were mostly positive; they appreciated the innovative approach to temperature measurement theme and were able to recognize the positive influence of it on their knowledge and skills.

\section{Discussion}

To summarize the results of our research we analyzed all the data obtained from didactic tests and questionnaires with regard to the following educational goals [26]:

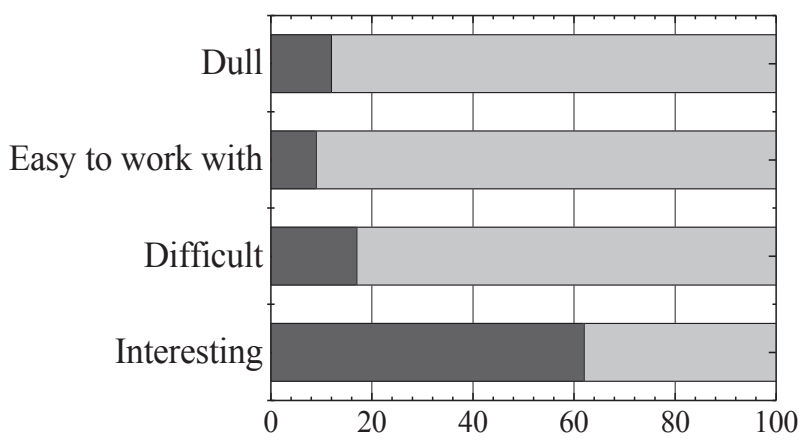

Figure 2. Pupils' attitudes towards REs (dark grey answers in percentage)

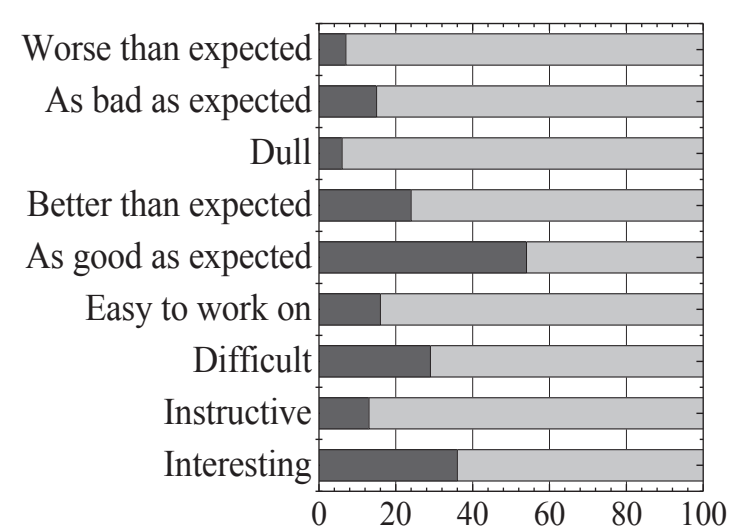

Figure 3. Pupils' attitudes towards projects (dark grey answers in percentage)

- Conceptual understanding - illustrate concepts and principles;

- Social skills - communication, team interaction and problem solving, leadership;

- Professional skills - technical/procedural skills; introduce students to the world of scientists and engineers in practice; application of knowledge to practice.

Conceptual understanding was measured on the basis of the results of the practical part of the first didactic test. We got the resulting value (in percentage) by comparing the results of TG and $\mathrm{CG}$ - we took into account all the values in TG which exceeded the mean score in CG.

The category "social skills" was considered with regard to questionnaire analysis - how many pupils appreciated the cooperation with groups as the benefit of the work on the project with REs.

It was rather difficult to measure the development of the goal "Professional skills", because we worked with pupils aged 12 or 13 . Some of them revealed the attitude that the activities conducted during the work on the project assignment would be useful for their future life. But we decided to measure this category in pursuance of the questionnaire item about the benefits of the work with REs. Because the ability to process data in the form of graphs and tables is important in many professions, we took this type of pupils' answers into account.

Fig. 4 shows the results of our evaluation. As can be seen, all three identified educational goals were getting developed by the majority of pupils involved in the research. The results show close agreement with the research of Ma and Nickerson [26] - the highest level of development was identified in the field of conceptual understanding, followed by professional skills.

In comparison with these authors, we detected the higher level of development in the field of social skills. This positive shift was caused by the implementation of REs to the project-based learning, which naturally supports cooperation and communication. 


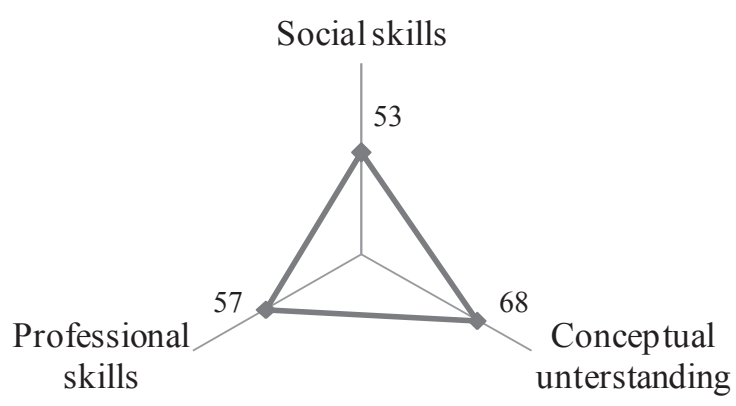

Figure 4. Educational goals of the research (in percentage)

\section{CONCLUSIONS AND Future WORK}

Among Physics teachers, there exists the prevailing opinion for the necessity of change in the teaching strategy. By using some activating teaching methods, the educators can move pupils/students from mindless memorization to understanding and appreciation. In the paper, we presented the use of the REs in teaching with the research aimed at the testing of the possible use of REs at primary schools. We introduced the unconventional way of teaching the theme "Temperature measurement". The main conclusions may be drawn as follows:

- The project was designed and implemented into the education process at four Slovak primary schools in compliance with the demands of national curriculum.

- The results confirmed the successful trial utilisation of REs in the pre-research.

- Pupils of TG gained a statistically higher level of knowledge and skills in data processing.

- In the second testing, they proved a higher level of the sustainability of knowledge and skills.

- They expressed mainly positive attitudes towards remote experimentation and project-based learning with the support of REs.

- In $12 \%$ of pupils we identified the positive shift in their perception of Physics.

The positive results gained in the research encourage us to continue in the proposed activities. We designed other projects with the support of REs for primary schools (in the $7^{\text {th }}$ grade) which are planned to be tested as the complex project-based learning at the chosen schools.

\section{ACKNOWLEDGEMENT}

The authors would like to thank the collective of coauthors participating on the design and development of the $1^{\text {st }}$ Slovak online natural science e-laboratory at Department of Physics, Faculty of Education, Trnava University in Trnava as well as the teachers involved in the research conducted at chosen primary schools.

\section{REFERENCES}

[1] F. M. Schaf, and C. E. Pereira, "Automation and Control Learning Environment with Mixed Reality Remote Experiments Architecture," International Journal of Online Engineering (iJOE), vol. 3, May 2007

[2] E. Scanlon, C. Colwell, M. Cooper, and T. Di Paolo, "Remote experiments, re-versioning and re-thinking science learning," Computers \& Education, vol. 43, pp. 153-163, Aug.-Sept. 2004. http://dx.doi.org/10.1016/j.compedu.2003.12.010
[3] C. Röhrig and A. Jochheim, "Java-based framework for remote access to laboratory experiments," IFAC/IEEE Symposium on Advances in Control Education, Gold Coast, Australia, 2000.

[4] X. Yue, E. et al., "Modular hardware design for distant-internet embedded systems engineering laboratory," Computer Applications in Engineering Education, vol. 17, pp. 389-397, Dec. 2009. http://dx.doi.org/10.1002/cae.20259

[5] M. T. Restivo, J. Mendes, A. M. Lopes, C. M. Silva, and F. Chouzal, "A remote laboratory in engineering measurement," IEEE Transactions on Industrial Electronics, vol. 56, pp. 48364843, Dec. 2009. http://dx.doi.org/10.1109/TIE.2008.2011479

[6] K. Žáková, "Maxima - An Open Alternative for Engineering Education, " International Journal of Engineering Pedagogy, vol. 1, pp. 27-30, 2011.

[7] L. Tkáč, and F. Schauer, "Dissemination of Science Among Students by Remote Experimentation," Procedia - social and behavioral sciences, vol. 47, pp. 1335-1340, 2012.

[8] L. Gomes, and S. Bogosyan, "Current Trends in Remote Laboratories," IEEE Transactions on Industrial Electronics, vol. 56, pp. 4744-4756, Dec. 2009. http://dx.doi.org/10.1109/ TIE.2009.2033293

[9] D. Lowe, P. Newcombe, and B. Stumpers, "Evaluation of the Use of Remote Laboratories for Secondary School Science Education," Research in Science Education, Published Online First: 20 July 2012. http://dx.doi.org/10.1007/s11165-012-9304-3

[10] S. Paladini, J. B. da Silva, G. R. Alves, B. R. Fischer, and J. B. da Mota Alves, "Using Remote Lab Networks to Provide Support to Public Secondary School Education Level," 11th IEEE International Conference on Computational Science and Engineering Workshops, 2008, pp. 275-280.

[11] S. J. White, "Enhancing instruction in mathematics and science in secondary schools: an innovative approach using remote sensing," International Geoscience and Remote Sensing Symposium, 2001, pp. 2480-2482.

[12] A. Coble et al., "Delivering authentic experiences for engineering students and professionals through e-labs," EDUCON $2010_{-}^{-}$ Annual Global Engineering Education Conference: The Future of Global Learning in Engineering Education, 2010, pp. 1085-1090.

[13] J. E. Corter et al., "Constructing Reality: A study of Remote, Hands-On, and Simulated Laboratories," ACM Transactions on Computer-Human Interaction, vol. 14, Aug. 2007. http://dx.doi.org/10.1145/1275511.1275513

[14] J. V. Nickerson, J. E. Corter, S. K. Esche, and C. Chassapis, "A model for evaluating the effectiveness of remote engineering laboratories and simulations in education," Computers \& Education, vol. 49, pp. 708-725, Nov. 2007. http://dx.doi.org/10.1016/j.compedu.2005.11.019

[15] D. Lang et al., "Pedagogical evaluation of remote laboratories in eMerge project," European Journal of Engineering Education, vol. 32, pp. 57-72, Jan. 2007. http://dx.doi.org/10.1080/ 03043790601055626

[16] M. Kostelníková, and M. Ožvoldová, “Teachers' attitudes towards remote experimentation," Journal of Technology and Information Education, vol. 4, pp. 21-27, Dec. 2012.

[17] M. Žovínová, and M. Ožvoldová, "Remote Experimentation at Primary Schools," Proceeding book of the Joint International Conference MPTL'16 - HSCI 2011, Ljubljana: University of Ljubljana, 2011. pp. 110-114.

[18] Ž. Gerhátová, "Project Learning with Components of Integrated elearning," Modern Education (Moderni vzdelávaní). Olomouc : Univerzita Palackého v Olomouci, 2011. pp. 111-115.

[19] F. Schauer, F. Lustig, J. Dvořák, and M. Ožvoldová, “An Easy to Build Remote Laboratory with Data Transfer using the Internet School Experimental System," Eur. J. Phys., vol. 29, pp. 753-765, July 2008. http://dx.doi.org/10.1088/0143-0807/29/4/010

[20] L. Tkáč, and F. Schauer, "Remote experiments for Integrated eLearning in Electricity and Magnetism course," Proceedings of the Conference REV 2011, Romania, Brasov. Wien : International association of Online Engineering, 2011. pp. 262-269.

[21] F. Schauer et al., "Slovak e-Laboratory of remote interactive experiments for university teaching by integrated e-learning strategy," ICETA 2008: 6th International Conference on 
Emerging eLearning Technologies and Applications, Stará Lesná, The High Tatras, Slovakia, 2008. pp. 467-472.

[22] M. T. Restivo, J. C. Marques, and T. Vieira, "Experimenta@ FEUP," CD-ROM Proceedings of the International Conference on Engineering Education, ICEE, 2007.

[23] The State Education Programme - Physics, 2011, http://www.statpedu.sk/files/documents/svp/2stzs/isced2/vzdelava cie oblasti/fyzika isced2.pdf.

[24] C. Wieman, and K. Perkins, "Transforming Physics Education," Physics Today, vol. 58, pp. 36-41, Nov. 2005. http://dx.doi.org/10.1063/1.2155756

[25] M. Palmer, "Science Education in Crisis: Science at Second Level," Chemistry in Action!, vol. 20, Spring 2000.

[26] J. Ma, and J. V. Nickerson, "Hands-on, Simulated and Remote Laboratories: A Comparative Literature Review," $A C M$ Computing Surveys, vol. 38, pp. 1-24, 2006. http://dx.doi.org/10.1145/1132960.1132961

\section{AUTHORS}

M. Kostelníková is with Trnava University in Trnava, a PhD student at the Department of Physics, Faculty of Education, Slovak Republic (e-mail: michaela.kostelnikova@tvu.sk).

M. Ožvoldová is with Trnava University in Trnava, Faculty of Pedagogy, Department of Physics, Slovak Republic (e-mail: mozvoldo@truni.sk) and Tomáš Bata University in Zlin, Faculty of Applied Informatics (e-mail: ozvoldova@fai.utb.cz).

This work was supported by the Grant Agency of the Ministry of Education of the Slovak Republic - KEGA No. 020TTU-4/2013 "Accreditation of personalized ICT natural sciences teacher's education centre" and No. 011TTU-4/2012 "Energy as a Category in Science Education via remote experiments and Integrated e-Learning". Submitted, 02 March 2013. Published as re-submitted by the authors 15 September 2013. 